Volume 4 Nomor 1, Februari 2019, halaman 41-48

\title{
PERBEDAAN KEMAMPUAN KONEKSI MATEMATIS PADA MATERI SEGITIGA BERDASARKAN JENIS APERSEPSI ALFA ZONE DAN MATHEMATICAL HABITS OF MIND LEVEL PADA MODEL PEMBELAJARAN KOOPERATIF TIPE STAD
}

\author{
THE DIFFERENCES OF MATHEMATICAL CONNECTION ABILITY \\ OF TRIANGLE SUBJECT MATTER BASED ON GIVING ALPHA ZONE \\ APPERCEPTION TYPE AND MATHEMATICAL HABITS OF MIND \\ LEVEL ON STAD TYPE OF COOPERATIVE LEARNING MODEL
}

\author{
Novi Widiyastuti ${ }^{1}$, Aan Juhana Senjaya ${ }^{2}$, Wiwit Damayanti Lestari ${ }^{3}$ \\ ${ }^{1}$ SMK Nusa Mangga Suci, Jln. PU Kabuptaen Desa Kalensari Widasari Indramayu 45271, \\ novi.widiyastuti11@gmail.com \\ ${ }^{2,3}$ Universitas Wiralodra, Jln. Ir. H. Djuanda Km3 Singaraja Indramayu 45213, \\ aansenjaya@yahoo.com, wiwitdamayantilestari@unwir.ac.id
}

\begin{abstract}
ABSTRAK
Tujuan penelitian ini untuk mengetahui perbedaan kemampuan koneksi matematis pada materi segitiga berdasarkan jenis apersepsi Alfa Zone, Mathematical Habits of Mind Level dan interaksi antara jenis apersepsi Alfa Zone dan Mathematical Habits of Mind Level pada model pembelajaran kooperatif tipe STAD. Penelitian ini adalah penelitian eksperimen dengan populasi kemampuan koneksi matematis seluruh siswa kelas VII SMP Negeri 3 Jatibarang tahun pelajaran 2017/2018. Sampel kelas diambil sebanyak dua kelas dengan menggunakan teknik cluster random samppling dengan cara diundi. Penelitian ini menggunakan analisis data ANAVA $2 \times 2$ by Level. Berdasarkan analisis data, diperoleh kesimpulan sebagai berikut: (1) Terdapat perbedaan rata-rata kemampuan koneksi matematis pada materi segitiga berdasarkan pemberian jenis apersepsi Alfa Zone pada model pembelajaran kooperatif tipe STAD; (2) Tidak terdapat perbedaan rata-rata kemampuan koneksi matematis pada materi segitiga berdasarkan Mathematical Habits of Mind Level Zone pada model pembelajaran kooperatif tipe STAD; (3) Tidak terdapat perbedaan interaksi kemampuan koneksi matematis pada materi segitiga berdasarkan pemberian jenis apersepsi Alfa Zone dan Mathematical Habits of Mind Level Zone pada model pembelajaran kooperatif tipe STAD.

Kata Kunci: Koneksi Matematis pada Materi Segitiga, Apersepsi Alfa Zone, Mathematical Habits of Mind, STAD
\end{abstract}

\begin{abstract}
The purpose of this study were to determine to know the differences mathematical connection ability of triangle subject matter based on Alpha Zone apperception type, Mathematical Habits of Mind Level and interaction between Alpha Zone apperception type and Mathematical Habits of Mind Level. This research were an experimental research with the population is mathematical connection ability of whole students of VII grade SMP Negeri 3 Jatibarang academic year 2017/2018. The sample was picked in two classes used cluster random sampling technique by lot. This research used data analysis ANAVA $2 \times 2$ by Level. Based on the result of data analysis, we concluded as follow: (1) There is average difference mathematical connection ability of triangle
\end{abstract}


Perbedaan Kemampuan Koneksi Matematis pada Materi Segitiga Berdasarkan Jenis Apersepsi Alfa Zone dan Mathematical Habits of Mind Level pada Model Pembelajaran Kooperatif Tipe STAD

subject matter based on Alpha Zone apperception type on STAD Type of Cooperative Learning Model; (2) There was not average difference mathematical connection ability of triangle subject matter based on Mathematical Habits of Mind Level on STAD Type of Cooperative Learning Model; (3) There was not average difference mathematical connection ability of triangle subject matter based on interaction between Alpha Zone apperception type and Mathematical Habits of Mind Level on STAD Type of Cooperative Learning Model.

Keywords: Mathematical Connection of Triangle Subjects Matter, Alpha Zone Apperception, Mathematical Habits of Mind, STAD

How to Cite: Widiyastuti, N., Senjaya, A. J., \& Lestari, W. D. (2019). Perbedaan Kemampuan Koneksi Matematis pada Materi Segitiga Berdasarkan Jenis Apersepsi Alfa Zone dan Mathematical Habits of Mind Level pada Model Pembelajaran Kooperatif Tipe STAD. Mathline: Jurnal Matematika dan Pendidikan Matematika, Vol.4, No.1, 41-48.

\section{PENDAHULUAN}

Matematika sangat penting dalam bidang pendidikan bahkan dalam kehidupan sehari-hari. Matematika bukan hanya ilmu tentang hitung menghitung saja melainkan matematika dapat menumbuhkan kemampuan berpikir logis, analitis, sistematis, kritis, kreatif, dan mampu bekerja sama. NCTM (2000) menyatakan bahwa terdapat lima kemampuan dasar matematika yang merupakan standar, yaitu pemecahan masalah (problem solving), penalaran dan pembuktian (reasoning and proof), komunikasi (communication), koneksi (connections), dan representasi (representation).

Salah satu kemampuan dasar matematika, yaitu kemampuan koneksi matematis. Menurut Hendriana \& Sumarmo (2014), Kemampuan koneksi matematis yaitu pemahaman yang dapat merelasikan atau menerapkan satu konsep matematika ke dalam konsep matematik lainnya atau ke dalam konsep disiplin ilmu lainnya. Oleh karena itu kemampuan koneksi sangatlah penting bagi siswa, karena nantinya siswa akan mudah memahami hubungan berbagai konsep matematika yang dapat diaplikasikan dalam kehidupan sehari-hari.

Penelitian yang dilakukan oleh Ramdhani, dkk. (2016), dipeoleh bahwa siswa hanya menghafal rumus tetapi tidak bisa memahaminya sehingga siswa belum bisa mengkoneksikan materi segitiga. Hal tersebut menunjukkan masih rendahnya kemampuan koneksi matematis siswa pada materi segitiga. Untuk mencapai kemampuan koneksi matematis pada materi segitiga sebagai guru haruslah memiliki inovasi agar siswa tidak merasa bosan dan malas untuk belajar, diantaranya dengan memberikan apersepsi Alfa Zone. 
Menurut Chatib (2016), apersepsi juga dipahami sebagai menciptakan kondisi (zona) alfa, yaitu kondisi paling iluminasi (cemerlang) proses kreatif otak seseorang. Kondisi alfa dikatakan sebagai kondisi paling baik untuk belajar sebab neuron (sel saraf) sedang berada dalam suatu harmoni (keseimbangan) yang mengakibatkan kondisi relaksasi seseorang. Oleh karena itu, dengan memberikan apersepsi Alfa Zone, dapat memberikan semangat siswa dalam proses belajar, sehingga siswa tidak merasa bosan dan malas. Dalam penelitian ini jenis apersepsi Alfa Zone yang diteliti adalah Ice Breaking dan Fun Story.

Apersepsi Alfa Zone Ice Breaking adalah stimulus pada awal belajar yang diperoleh dari pengamatan dan pengalaman yang bertujuan meraih perhatian peserta didik pada saat kondisi paling baik untuk belajar dengan kegiatan berupa permainan untuk memecahkan kebekuan dan membangkikan semangat. Sedangkan, apersepsi Alfa Zone Fun Story adalah stimulus pada awal belajar yang diperoleh dari pengamatan dan pengalaman yang bertujuan meraih perhatian peserta didik pada saat kondisi paling baik untuk belajar dengan memberikan cerita singkat, gambar atau teka-teki yang mengandung humor. Hal ini dapat membuat siswa mudah untuk diarahkan dalam proses belajar sehingga mampu mengkoneksikan matematika. Namun, selain hal-hal di atas, sikap dan cara berpikir matematis siswa juga ikut mempengaruhi proses belajar siswa.

Sikap merupakan salah satu cerminan dari diri siswa. Ketika sikap siswa kurang baik maka akan berpengaruh terhadap cara berpikir matematisnya. Nurmaulita (2014) menyatakan bahwa, sikap peserta didik untuk mencapai produk sains dapat ditempuh dengan sikap ilmiah dan kebiasaan berfikir aktif dalam pembelajaran. Kebiasaan berfikir positif dalam kegiatan belajar mengajar ini dapat membentuk Habits of Mind siswa untuk mencapai keberhasilan belajarnya.

Oleh karena itu, sikap baik sangat penting untuk dimiliki siswa agar membentuk kebiasaan berpikir yang baik pula yang nantinya akan berdampak pada keberhasilan dalam proses belajar. Begitupun dalam pembelajaran matematika, sangat diperlukan sikap yang baik agar dapat menghadapi masalah yang bersifat matematis.

Kesulitan siswa dalam mengkoneksikan masalah-masalah pada materi matematika yang dihadapi dengan konsep pada materi matematika yang diperoleh bukan hanya dipengaruhi oleh siswa, materi matematika, maupun kebiasaan berpikir siswa, melainkan juga dari kreativitas guru dalam mengajar. Dalam pembelajaran di kelas, guru seharusnya bisa membuat siswa menemukan dan membangun pengetahuan yang dimiliki. Salah satu cara agar siswa dapat menemukan dan membangun pengetahuan tersebut adalah dengan menggunakan model pembelajaran kooperatif tipe STAD (Student Team Achievement 
Perbedaan Kemampuan Koneksi Matematis pada Materi Segitiga Berdasarkan Jenis Apersepsi Alfa Zone dan Mathematical Habits of Mind Level pada Model Pembelajaran Kooperatif Tipe STAD

Division). Menurut Trianto (2013), STAD merupakan salah satu tipe dari model pembelajaran kooperatif dengan menggunakan kelompok-kelompok kecil dengan jumlah anggota tiap kelompok 4-5 orang siswa secara heterogen. Sehingga dengan menerapkan apersepsi Alfa Zone dan Mathematical Habits of Mind pada Model Pembelajaraan Kooperatif Tipe STAD dapat mengembangkan kemampuan koneksi matematis siswa.

Tujuan dalam penelitian ini adalah mengetahui apakah terdapat perbedaan rata-rata kemampuan koneksi matematis pada materi segitiga berdasarkan pemberian jenis apersepsi Alfa Zone pada model pembelajaran kooperatif tipe STAD; mengetahui apakah terdapat perbedaan rata-rata kemampuan koneksi matematis pada materi segitiga berdasarkan Mathematical Habits of Mind Level Zone pada model pembelajaran kooperatif tipe STAD; mengetahui apakah terdapat perbedaan interaksi kemampuan koneksi matematis pada materi segitiga berdasarkan pemberian jenis apersepsi Alfa Zone dan Mathematical Habits of Mind Level Zone pada model pembelajaran kooperatif tipe STAD.

\section{METODE PENELITIAN}

Metode penelitian yang digunakan dalam penelitian ini adalah metode penelitian eksperimen. Kedua kelas eksperimen diberikan angket Mathematical Habits Of Mind Level, kemudian diurutkan menjadi 3 tingkat yaitu tinggi, sedang, dan rendah, setelah itu kedua kelas sampel masing-masing diberi perlakuan, kelas pertama diberi perlakuan dengan memberikan apersepsi Alfa Zone Fun Story pada model pembelajaran kooperatif tipe STAD dengan materi pembelajaran segitiga dan kelas kedua diberi perlakuan Alfa Zone Ice Breaking pada model pembelajaran kooperatif tipe STAD dengan materi pembelajaran segitiga. Setelah diberi perlakuan kedua kelas sampel diberikan tes akhir untuk mengetahui kemampuan koneksi matematis pada materi segitiga.

Populasi dalam penelitian ini adalah seluruh kemampuan koneksi matematis pada materi segitiga siswa kelas VII SMP Negeri 3 Jatibarang tahun ajaran 2017/2018 yang terbagi menjadi delapan kelas, yaitu VII A, VII B, VII C, VII D, VII E, VII F, VII G, dan VII H. Teknik pengambilan sampel dalam penelitian ini menggunakan cluster random sampling karena populasi sudah dikelompokan dalam delapan kelas dan akan dipilih dua kelas sebagai sampel. Setelah dilakukan pengundian, terpilih kelas VII C dan VII F. Dengan demikian kelas VII F digunakan untuk kelas eksperimen 1, yaitu kelas yang pembelajaran diberikan aperpsepsi Alfa Zone Ice Breaking pada model pembelajaran kooperatif tipe STAD dengan materi pembelajaran segitiga, dan VII C digunakan untuk kelas eksperimen 2, yaitu kelas yang pembelajarannya diberikan apersepsi Alfa Zone Fun 
Story pada model pembelajaran kooperatif tipe STAD dengan materi pembelajaran segitiga.

Instrumen yang digunakan untuk mengukur Mathematical Habits Of Mind Level berupa angket, sedangkan untuk mengukur kemampuan koneksi matematis pada materi segitiga menggunkan tes uraian. Teknik analisis data yang digunakan adalah Uji ANAVA dua jalan kemudian dilanjutkan uji lanjut (Pos-hoc test) dari Scheffe, apabila terdapat perbedaan yang signifikan. Analisis data yang dilakukan, menggunkan bantuan software PESTRIPP (Senjaya, 2017) dengan taraf signifikan $\alpha=0,05$.

\section{HASIL DAN PEMBAHASAN}

Mathematical Habits Of Mind Level dikategorikan menjadi tiga kelompok (tinggi, sedang, dan rendah), namun berdasarkan hasil penelitian di lapangan, diperoleh hasil Mathematical Habits of Mind Level adalah tinggi dan sedang. Sehingga untuk menganalisis data hasil post test digunakan ANAVA dua jalan $2 \times 2$ by level dua kategori (tinggi dan sedang). Berikut ini data hasil penelitian:

Tabel 1. Ringkasan Data Hasil Penelitian

\begin{tabular}{|c|c|c|c|c|c|c|}
\hline \multirow{2}{*}{$\mathbf{A}$} & \multicolumn{4}{|c|}{$M$} & \multirow{2}{*}{\multicolumn{2}{|c|}{$\sum$}} \\
\hline & \multicolumn{2}{|c|}{$\mathbf{M}_{1}$} & \multicolumn{2}{|c|}{$\mathbf{M}_{2}$} & & \\
\hline \multirow{3}{*}{$\mathrm{A}_{1}$} & $\mathrm{n}_{11}=$ & 17 & $\mathrm{n}_{12}=$ & 7 & $\mathrm{nA}_{1}=$ & 24 \\
\hline & $\overline{\mathrm{y}}=$ & 24,76 & $\overline{\mathrm{y}}=$ & 28,86 & $\overline{\mathrm{y}}=$ & 25,96 \\
\hline & $\mathrm{s}=$ & 7,69 & $\mathrm{~s}=$ & 6,15 & $\mathrm{~s}=$ & 10,77 \\
\hline \multirow{3}{*}{$\mathrm{A}_{2}$} & $\mathrm{n}_{21}=$ & 16 & $\mathrm{n}_{22}=$ & 13 & $\mathrm{nA}_{2}=$ & 29 \\
\hline & $\overline{\mathrm{y}}=$ & 19,81 & $\overline{\mathrm{y}}=$ & 23,77 & $\overline{\mathrm{y}}=$ & 21,59 \\
\hline & $\mathrm{s}=$ & 4,96 & $\mathrm{~s}=$ & 7,84 & $\mathrm{~s}=$ & 6,60 \\
\hline \multirow{3}{*}{$\sum M$} & $\mathrm{nM}_{1}=$ & 33 & $\mathrm{nM}_{2}=$ & 20 & $\mathrm{nT}=$ & 53 \\
\hline & $\overline{\mathrm{y}}=$ & 22,36 & $\overline{\mathrm{y}}=$ & 25,55 & $\overline{\mathrm{y}}=$ & 23,57 \\
\hline & $\mathrm{s}=$ & 6,89 & $\mathrm{~s}=$ & 7,55 & $\mathrm{~s}=$ & 7,24 \\
\hline
\end{tabular}

Sebelum melakukan Uji ANAVA dua jalan, penulis melakukan uji normalitas dan uji homogenitas sebagai uji prasyarat. Pengujian prasyarat uji normalitas dilakukan dengan menggunakan Uji Liliefors, diperoleh bahwa populasi berdistribsi normal, kemudian uji homogenitas menggunakan Uji Bartlett, diperoleh bahwa varian kelompok homogen. Kemudian melakukan Uji ANAVA dua jalan, diperoleh data sebagai berikut: 
Perbedaan Kemampuan Koneksi Matematis pada Materi Segitiga Berdasarkan Jenis Apersepsi Alfa Zone dan Mathematical Habits of Mind Level pada Model Pembelajaran Kooperatif Tipe STAD

Tabel 2. Hasil Perhitungan ANAVA Dua Jalan

\begin{tabular}{ccccccc}
\hline \multirow{2}{*}{ Sumber Variansi } & \multirow{2}{*}{ JK } & \multirow{2}{*}{ Db } & \multirow{2}{*}{ RJK } & Fo & \multicolumn{2}{c}{ Fkritis } \\
\cline { 6 - 7 } & & & & Fk $_{\mathbf{1}}$ & Fk $_{\mathbf{2}}$ \\
\hline Antar B & 251,03 & 1 & 251,03 & 5,39 & 0,0010 & 5,347 \\
Antar M & 126,43 & 1 & 126,43 & 2,72 & 0,0010 & 5,347 \\
Antar Interaksi & 68,90 & 1 & 68,90 & 1,56 & 0,0010 & 5,347 \\
AxM & 2280,66 & 49 & 46,54 & & & \\
Dalam (SEM) & 2727,02 & 52 & & & & \\
Total & 27,5 & & & & &
\end{tabular}

Keterangan: $\mathrm{F}_{\mathrm{k}_{1}}=\mathrm{F}_{(0,025 ; 1 ; 49)} ; \mathrm{F}_{\mathrm{k} 2}=\mathrm{F}_{(0,975 ; 1 ; 49)}$

Hasil uji hipotesis yang pertama menunjukan bahwa terdapat perbedaan kemampuan koneksi matematis pada materi segitiga berdasarkan jenis apersepsi Alfa Zone pada model pembelajaran kooperatif tipe STAD. Hal ini dikarenakan terdapat bedanya perlakuan yang diberikan. Kelas eksperimen I diberikan jenis apersepsi Alfa Zone Ice Breaking sedangkan kelas eksperimen II diberikan jenis apersepsi Alfa Zone Fun Story. Dilihat dari rata-rata yang diperoleh dari hasil penelitian bahwa pemberian jenis aperspsi Alfa Zone Ice Breaking lebih baik dari pada pemberian jenis aperspsi Alfa Zone Fun Story. Penelitian ini mendukung pendapat Mansur (2015) yang menyatakan bahwa, Ice breaking merupakan kegiatan yang dapat memecahkan kebekuan, membangkitkan semangat siswa dalam belajar, bahkan bisa digunakan untuk pemantapan konsep kembali masuk ke kondisi alfa. Dengan semangat belajar yang tinggi siswa dapat mengikuti pembeajaran dengan baik dan hasil belajar nya pun akan baik. Hasil belajar di sini adalah kemampuan koneksi matematis pada materi segitiga. Hasil penelitian ini juga sejalan dengan penelitian lain yang dilakukan oleh Bakhtiar (2015) yang menyimpulkan bahwa, hasil penelitian yang dilakukan dengan pemberian Ice Breaking pada pembelajaran dapat meningkatkan keterampilan sosial siswa. Lain hal nya dengan pemberian jenis apersepsi Alfa Zone Fun Story, karena siswa memiliki daya humor berbeda, sehingga mengakibatkan tidak maksimalnya stimulus di awal pembelajaran.

Hasil uji hipotesis kedua menunjukan bahwa tidak terdapat perbedaan rata-rata kemampuan koneksi matematis pada materi segitiga berdasarkan kategori Mathematical Habits Of Mind Level. Kemungkinan faktor tidak adanya perbedaan kemampuan koneksi matematis pada materi segitiga berdasarkan kategori Mathematical Habits Of Mind Level dikarenakan siswa mengisi angket tidak sesuai dengan dirinya sendiri, dan masih melihat jawaban temannya. Penelitian ini tidak mendukung pendapat Hendriana, dkk. (2017) yang 
menyatakan bahwa, siswa yang memiliki Habits Of Mind tinggi maka akan memiliki keprbadian cakap, kreatif dan mandiri. Hasil penelitian inipun tidak sejalan dengan penelitian Nurmaulita (2014) yang menyatakan bahwa, peningkatan Habits Of Mind penting dalam proses pembelajaran. Mathematical Habits Of Mind Level yang dimiliki siswa dapat berpengaruh dalam keberhasilan pembelajaran matematika khususnya dalam meningkatkan kemampuan koneksi matematis pada materi segitiga. Selain itu, hasil tersebut juga tidak sejalan dengan penelitian Miliyawati (2014) yang menyatakan bahwa, dengan memberikan strategi Mathematical Habits Of Mind, jika kebiasaan-kebiasaan dilakukan secara konsisten dalam pembelajaran maka akan menghasilkan peserta didik yang unggul dalam kemampuan berpikir matematis.

Hasil uji hipotesis ketiga menunjukan bahwa tidak terdapat perbedaan interaksi kemampuan koneksi matematis pada materi segitiga berdasarkan interaksi antara pemberian jenis apersepsi Alfa Zone dan Mathematical Habits Of Mind Level. Kemungkinan-kemungkinan tidak adanya perbedaan interaksi dikarenakan dipengaruhi oleh beberapa faktor, diantaranya kesiapan siswa dengan pemberian jenis apersepsi Alfa Zone, siswa merasa tertarik dengan pemberian jenis apersepsi Alfa Zone dan mengulangulang apersepsi Alfa Zone tersebut sehingga mengurangi waktu untuk mempelajari materi segitiga. Kemudian temuan lain dalam penelitian ini adalah kejujuran siswa mengisi angket masih kurang, masih banyak siswa melihat pilihan temannya, sehingga hasilnya relatif sama. Sehingga hasil tersebut tidak sejalan dengan penelitian yang dilakukan Susanti (Handayani, 2015) yang menemukan bahwa siswa yang memiliki Mathematical Habits Of Mind Level tinggi dapat menyelesaikan masalah dengan sistematis, memiliki ketekunan dalam menyelesaikan masalah dan memiliki cara alternatif dalam menyelesaikan permasalahan matematika.

\section{KESIMPULAN}

Berdasarkan hasil penelitian dan pembahasan, maka dapat disimpulkan bahwa:

1) Terdapat perbedaan rata-rata kemampuan koneksi matematis pada materi segitiga berdasarkan pemberian jenis apersepsi Alfa Zone pada model pembelajaran kooperatif tipe STAD.

2) Tidak terdapat perbedaan rata-rata kemampuan koneksi matematis pada materi segitiga berdasarkan Mathematical Habits Of Mind Level pada model pembelajaran kooperatif tipe STAD. 
Perbedaan Kemampuan Koneksi Matematis pada Materi Segitiga Berdasarkan Jenis Apersepsi Alfa Zone dan Mathematical Habits of Mind Level pada Model Pembelajaran Kooperatif Tipe STAD

3) Tidak terdapat perbedaan kemampuan koneksi matematis pada materi segitiga berdasarkan interaksi pemberian jenis apersepsi Alfa Zone dan Mathematical Habits Of Mind Level pada model pembelajaran kooperatif tipe STAD.

Adapun saran untuk peneliti lebih lanjut, diharapkan dapat melakukan penelitian lanjutan mencakup pokok bahasan yang lebih luas, persiapan yang lebih matang, memiliki cadangan solusi untuk menghadapi siswa, memilih tempat penelitian yang tepat, waktu penelitian yang tepat dan dalam jangka waktu yang lebih lama.

\section{DAFTAR PUSTAKA}

Bakhtiar, M. I. (2015). Pengembangan Video Ice breaking Sebagai Media Bimbingan Konseling Dalam Meningkatkan Keterampilan Sosial. Jurnal Psikologi Pendidikan \& Konseling, Vol.1, No.2, 150-162.

Chatib, M. (2016). Gurunya Manusia. Bandung: Kaifa.

Handayani, A. D. (2015). Mathematical Habits Of Mind: Urgensi dan Penerapannya Dalam Pembelajaran Matematika. Jurnal Math Educator Nusantara, Vol.1, No.2, 223-230.

Hendriana, H \& Sumarmo, U. (2014). Penilaian Pembelajaran Matematika. Bandung: PT. Refika Aditama.

Hendriana, H., Roheti, E. E., \& Sumarmo, U. (2017). Hard Skill dan Soft Skill Matematik Siswa. Bandung: PT. Refika Aditama.

Mansur. 2015. Menciptakan Pembelajaran Melalui Apersepsi. [Online] Tersedia di http://www.lppmsulsel.net/v2/index.php?option=com_content\&view=article\&id=3 27:pembelajaran-efektif-apersepsi\&catid=42:ebuletin\&Itemid $=215 \quad[25$ Oktober 2017].

Miliyawati, B. (2014). Urgensi Strategi Disposition Habits of MInd Matematis. Jurnal Ilmiah Program Studi Matematika STKIP Siliwangi Bandung, Vol.3, No.2, 174188.

NCTM. (2000). Principles and Standards for Shcool Mathematics. Reston: NCTM.

Nurmaulita. (2014). Pembentukan Habits Of Mind Melalui Pembelajaran Salingtemas Pada Mata Pelajaran Fisika. Jurnal Pendidikan Fisika, 3(1), 53-58.

Ramdhani, M. R., Widiyastuti, E., \& Subekti, F. E. (2016). Analisis Kemampuan Koneksi Matematis Siswa Kelas VII SMP Negeri 1 Kembaran Materi Bangun Datar. Prosiding Seminar Matematika dan Penddidikan Matematika, 403-414.

Senjaya, A. J. (2017). Statistika Terapan untuk Penelitian Bidang Pendidikan dan Pengajaran. Indramayu: FKIP Unwir.

Trianto. (2013). Mendesain Model Pembelajaran Inofatif-Progresif. Jakarta: Kencana Prenada Media Group. 